\title{
CONTROL STRATEGIES BASED ON THE MATHEMATICAL MODEL OF AN INDUCTION MOTOR
}

\author{
Ahmad N. Al-Husban \\ Associate Professor Al-Balqa Applied University Faculty of \\ Engineering Technology Amman-Jordan
}

(Received March 24, 2008 Accepted May 5, 2008)

\begin{abstract}
This paper presents the application of intelligent control in the induction motor drive. In this paper, a strategy for induction motor speed control is proposed. This strategy is based on a new control stator current strategy. The proposed technique is based on the principle that the flux level in a machine can be adjusted to give the required performance for a given value of speed and load torque. The main advantage of the proposed technique is its simple structure. The optimum flux level is a function of the machine load and speed requirements. The proposed strategy with the method of operation under the condition of constant voltage to frequency ratio and field oriented control is achieved. Digital computer simulation results are obtained to demonstrate the effectiveness of the proposed method.
\end{abstract}

\section{1- INTRODUCTION}

The world's generated electric energy is consumed by electric machines. Improving efficiency in electric drives is important, mainly, for two reasons: economic saving and reduction of environmental pollution.

Induction motors have a high efficiency at rated speed and torque. However, at light loads, the iron losses increase dramatically, reducing the efficiency.

The main induction motor losses are: the stator and rotor copper losses, iron losses, mechanical losses and stray losses. The efficiency which decreases with increasing losses can be improved by minimizing the losses. Copper losses reduce with decreasing the stator and the rotor currents while the core losses essentially increase with increasing air-gap flux density. A study of the copper and core losses components reveals that their trends conflict. When the core losses increase, the copper losses tend to decrease.

However, for a given load torque, there is an air-gap flux density at which the total losses are minimized. Hence, the electrical losses minimization process ultimately comes down to the selection of the appropriate air-gap flux density of operation. Since the air-gap flux density must be variable when the load is changing, control schemes in which the (rotor, air-gap) flux linkage is constant will yield suboptimal efficiency operation, especially when the load is light. Then to improve the motor efficiency, the flux must be reduced when the motor operates under light load conditions, obtaining a balance between copper and iron losses. 
The challenge to engineers, however, is to be able to predict the appropriate flux values at any operating points over the complete torque and speed range, which will minimize the machine losses, hence maximizing the efficiency [1-4].

In this paper, a new control is proposed which is simple in structure and has the straightforward goal of maximizing the efficiency for a given load torque. Digital copmuter simulation results are obtained to demonstrate the effectiveness of the proposed method.

\section{2- INDUCTION MOTOR MODEL}

The dynamic equations of the three-phase induction motor can be expressed in the synchronous reference frame. Stator and rotor voltage equations in the synchronous reference frame are:

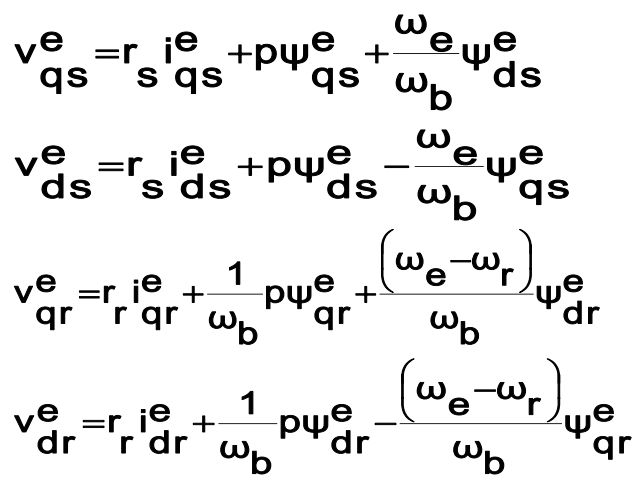

Where $\mathbf{v}_{\mathbf{q} \mathbf{s}}^{\mathbf{e}}$ and $\mathbf{v}_{\mathbf{q r}}^{\mathbf{e}}$ are the quadrature axis stator and rotor voltages in the synchronous reference frame, $v_{\mathbf{d s}}^{e}$ and $v_{\mathbf{d r}}^{e}$ are the direct axis stator and rotor voltages in the synchronous reference frame, $r_{\mathbf{S}}$ and $r_{r}$ are the stator and rotor winding resistances, $\psi_{\mathrm{qs}}^{\mathrm{e}}$ is the quadrature axis stator flux linkage in the synchronous reference frame, $\psi_{\mathrm{ds}}^{\mathrm{e}}$ and $\boldsymbol{\psi}_{\mathrm{qr}}^{\mathrm{e}}$ are the direct axis stator and rotor flux linkages in the synchronous reference frame, $i_{q s}^{e}$ and $i_{q r}^{e}$ are the quadrature axis stator and rotor currents in the synchronous reference frame, $i_{d s}^{e}$ and $i_{d r}^{e}$ are the direct axis stator and rotor currents in the synchronous reference frame, $\omega_{\mathbf{e}}$ and $\omega_{r}$ are the synchronous and rotor speeds $(\mathrm{rad} / \mathrm{sec}), \omega_{\mathrm{b}}$ is the base electrical angular velocity $(\mathrm{rad} / \mathrm{sec})$ and $p=\frac{d}{d t}$ is the time derivative.

The stator and rotor flux linkages of the quadrature and direct axis can be related to $d-q$ currents in the synchronous reference frame as : 


$$
\begin{aligned}
& \boldsymbol{\Psi}_{\mathbf{q} s}^{\mathbf{e}}=X_{s s_{\text {qs }}^{i e}}+X_{M}{ }_{\text {qr }}^{\text {ie }} \\
& \Psi_{d s}^{e}=X_{s s}{ }^{i e} d s^{e}+X_{M}{ }_{d r} e_{r}
\end{aligned}
$$

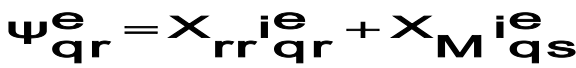

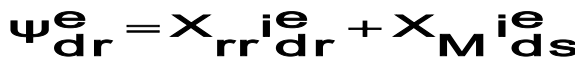

Where $X_{M}$ is the magnetizing reactance and

$$
\begin{aligned}
& X_{s s}=X_{M}+X_{I s} \\
& X_{r r}=X_{M}+X_{I r}
\end{aligned}
$$

It is assumed that all rotor variables are referred to the stator by the appropriate turn ratio. If the stator currents are considered as inputs and rotor windings are short circuited, the dynamic equations may be expressed as:

$$
\begin{aligned}
& 0=\frac{r_{r}}{X_{r r}}\left(\Psi_{q r}^{e}-X_{M_{q}^{i}}^{e}\right)+\frac{\omega_{s}}{\omega_{b}} \Psi_{d r}^{e}+\frac{1}{\omega_{b}} p \Psi_{q r}^{e} \\
& 0=\frac{r_{r}}{X_{r r}}\left(\psi_{d r}^{e}-X_{M^{i}}^{e}\right)-\frac{\omega_{s}}{\omega_{b}} \psi_{q r}^{e}+\frac{1}{\omega_{b}} p \psi_{d r}^{e}
\end{aligned}
$$

Where $\omega_{\mathrm{s}}=\omega_{\mathrm{e}}-\omega_{\mathrm{r}}$ is the slip frequency.

$$
\text { The electromagnetic torque can be expressed as: }
$$

$$
\mathbf{T}_{\mathbf{e}}=\mathbf{K}\left(\boldsymbol{\psi} \underset{\mathbf{d r}}{\mathbf{e}} \mathbf{i}_{\mathbf{q S}}^{\mathbf{e}}-\boldsymbol{\psi}_{\mathbf{q r}}^{\mathbf{e}} \mathbf{i}_{\mathrm{ds}}^{\mathbf{e}}\right)
$$

Where: $\mathbf{K}=\left(\frac{3}{2}\right)\left(\frac{\mathbf{P}}{2}\right)\left(\frac{1}{\boldsymbol{\omega}_{\mathbf{b}}}\right)$

If the currents are selected as independent variables, the voltage equation in dq model becomes:

$$
\left[\begin{array}{c}
\mathbf{v}_{\mathbf{q s}} \\
\mathbf{v}_{\mathbf{d s}} \\
\mathbf{v}_{\mathbf{q r}}^{\prime} \\
\mathbf{v}_{\mathbf{d r}}^{\prime}
\end{array}\right]=\left[\begin{array}{cccc}
\mathbf{r}_{\mathbf{s}}+\frac{\mathbf{p}}{\omega_{\mathbf{b}}} \mathbf{X}_{\mathbf{S s}} & \frac{\omega}{\omega_{\mathbf{b}}} \mathbf{X}_{\mathbf{S s}} & \frac{\mathbf{p}}{\omega_{\mathbf{b}}} \mathbf{X}_{\mathbf{M}} & \frac{\omega}{\omega_{\mathbf{b}}} \mathbf{X}_{\mathbf{M}} \\
-\frac{\omega}{\omega_{\mathbf{b}}} \mathbf{X}_{\mathbf{S S}} & \mathbf{r}_{\mathbf{s}}+\frac{\mathbf{p}}{\omega_{\mathbf{b}}} \mathbf{X}_{\mathbf{S S}} & -\frac{\omega}{\omega_{\mathbf{b}}} \mathbf{X}_{\mathbf{M}} & \frac{\mathbf{p}}{\omega_{\mathbf{b}}} \mathbf{X}_{\mathbf{M}} \\
\frac{\mathbf{p}}{\omega_{\mathbf{b}}} \mathbf{X}_{\mathbf{M}} & \left(\frac{\omega-\omega_{\mathbf{r}}}{\omega_{\mathbf{b}}}\right) \mathbf{X}_{\mathbf{M}} & \mathbf{r}_{\mathbf{r}}^{\prime}+\frac{\mathbf{p}}{\omega_{\mathbf{b}}} \mathbf{X}_{\mathbf{r r}}^{\prime} & \left(\frac{\omega-\omega_{\mathbf{r}}}{\omega_{\mathbf{b}}}\right) \mathbf{X}_{\mathbf{r r}}^{\prime} \\
-\left(\frac{\omega-\omega_{\mathbf{r}}}{\omega_{\mathbf{b}}}\right) \mathbf{X}_{\mathbf{M}} & \frac{\mathbf{p}}{\omega_{\mathbf{b}}} \mathbf{X}_{\mathbf{M}} & -\left(\frac{\omega-\omega_{\mathbf{r}}}{\omega_{\mathbf{b}}}\right) \mathbf{X}_{\mathbf{r r}}^{\prime} & \mathbf{r}_{\mathbf{r}}^{\prime}+\frac{\mathbf{p}}{\omega_{\mathbf{b}}} \mathbf{X}_{\mathbf{r r}}^{\prime}
\end{array}\right]\left[\begin{array}{c}
\mathbf{i}_{\mathbf{q s}} \\
\mathbf{i}_{\mathbf{d s}} \\
\mathbf{i}_{\mathbf{q}}^{\prime} \\
\mathbf{i}_{\mathbf{d r}}^{\mathbf{d r}}
\end{array}\right]
$$

Where: $\omega$ is the reference frame speed.

The balance equation of motion is given by:

$$
\mathbf{T}_{\mathbf{e}}=\mathbf{T}_{\mathbf{L}}+\mathbf{J} \frac{\mathbf{d} \boldsymbol{\omega} \mathbf{r}}{\mathbf{d t}}
$$

Where: $T_{L}$ is the load torque and $\mathbf{J}$ is the moment of inertia of the drive system. 


\section{3- FIELD ORIENTED CONTROL}

In the Field Oriented Control Strategy, the indirect method of control, $\theta_{\mathrm{e}}=\mathbf{0}$ is selected such that $\boldsymbol{\Psi}_{\mathbf{q} \mathbf{r}}^{\mathbf{e}}$ is identically zero [5-7]. Then we get:

$$
\begin{aligned}
& 0=-\frac{r_{r} X_{M_{i} e}^{e}}{X_{r r}}+\frac{\omega_{s}}{\omega_{b}} \Psi_{d r}^{e} \\
& 0=\frac{r_{r}}{X_{r r}}\left(\Psi_{d r}^{e}-X_{M_{d s}^{i}}^{e}\right)+\frac{1}{\omega_{b}} p \Psi_{d r}^{e}
\end{aligned}
$$

If $\mathbf{i}_{\mathbf{d s}}^{\mathbf{e}} \mathbf{i s}$ is controlled so that it remains constant, this implies that

$$
p \Psi_{d r}^{e}=0
$$

and

$$
\Psi_{d r}^{e}=X_{M}^{i e}
$$

By substituting and solving for $\omega_{\mathrm{s}}$ :

$$
\omega_{S}=\left(\frac{\omega_{b} \mathbf{r}_{r}}{X_{r r}}\right)\left(\frac{i_{q s}^{e}}{i_{d s}^{e}}\right)
$$

The electromagnetic torque can be expressed as:

$$
\mathbf{T}_{\mathbf{e}}=\mathbf{K} \frac{\mathbf{X}_{\mathbf{M}}^{2}}{\mathbf{X}_{\mathbf{r r}}} \underset{\mathbf{q s}}{\mathbf{e}} \stackrel{\mathbf{i}}{\mathbf{e}}
$$

The command of magnetization current is $\mathbf{i}_{\mathbf{d s}}^{\mathbf{e}^{*}}$, which is normally constant and the control of the torque component is achieved by $\mathrm{i}^{*}$. The three-phase reference qs

currents $i_{\text {as }}^{*}, i_{b s}^{*}$ and $i_{\text {cs }}^{*}$ are supplied to the inverter control system. The d-axis current is set to a constant value, which produces rated torque at rated stator flux. The corresponding slip is calculated in accordance with this condition. After extensive manipulation, the value of the d-axis current which yields rated torque at rated stator flux can be calculated by :

$$
\mathrm{i}_{\mathrm{ds}}^{\mathrm{e}}=\sqrt{\frac{1}{2 \mathrm{u}}+\frac{1}{2 \mathrm{u}} \sqrt{1-\frac{4 \mathrm{a}\left(\mathrm{X}^{\prime \prime}\right)^{2} \mathrm{X}_{\mathrm{rr}}^{2}}{\mathrm{X}_{\mathrm{m}}^{4}}}}
$$




\section{4- CONTROL STRATEGIES}

In the following proposed strategies, it is convenient to select $T_{e}, \omega_{r}$ and $\omega_{s}$ as independent variables. All other variables, such as stator or rotor flux amplitude, efficiency or power factor, can be expressed in terms of the selected independent variables.

When defining the alternative operating strategies, it is assumed that the torque and speed are given whereupon the slip frequency is adjusted so as to achieve certain characteristics. These characteristics include the maximization of power factor, minimization of stator current, maximization of efficiency, ... etc.

Therefore, it is convenient to relate the slip speed versus the air gap flux as shown in Fig. (1) to Fig.(3). The following sections show the details about the proposed control strategies based on the loss model controller.

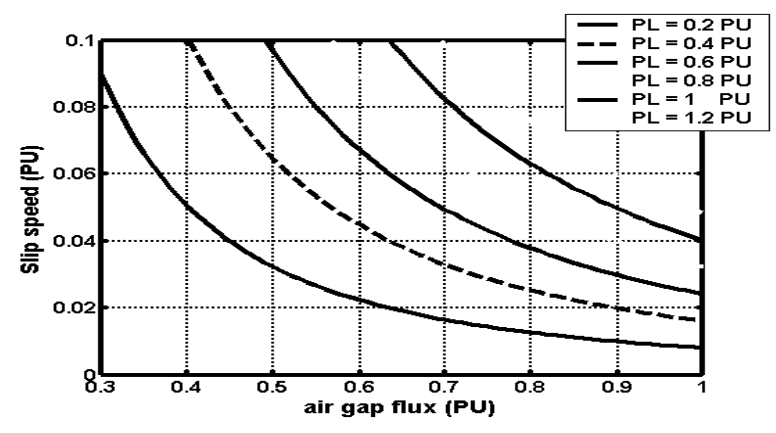

Fig. (1): Air gap flux versus slip speed at various load powers.

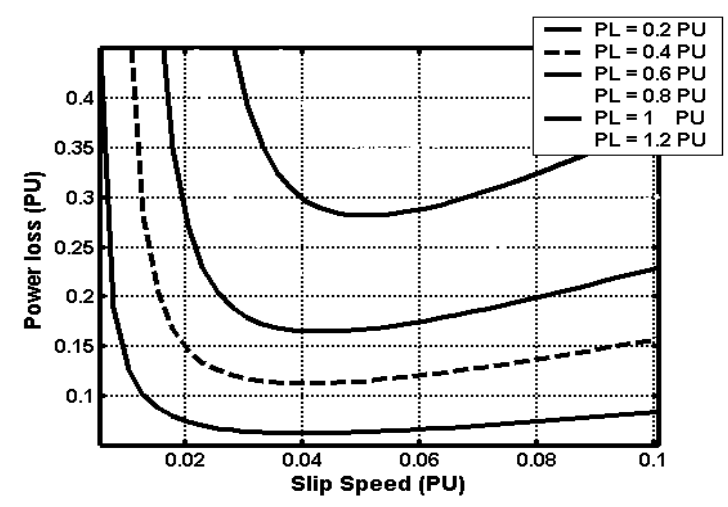

Fig. (2): Power losses versus slip speed of induction motor at various levels of load power. 


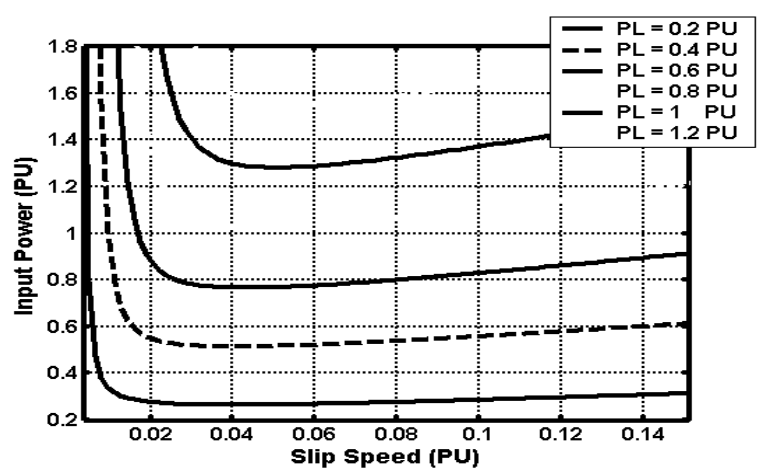

Fig. (3): Input power versus slip frequency of induction motor at various levels of load power.

\section{STATOR CURRENT STRATEGY}

In the Minimum Stator Current Strategy, the slip frequency is adjusted so that the stator current of the induction motor presented is minimized. The air gap flux or the slip frequency is controlled so that the minimum stator current is obtained.

The required point can be noticed in this figure. It is obvious that at a certain load power, there is a certain value of slip frequency at which the minimum stator current occurs.The task of proposed controller is to find that value of flux or slip frequency at which the minimum stator current occurs. At certain load torque and rotor speed, the proposed controller determines the slip frequency $\omega_{\mathrm{s}}$ at which the minimum stator current occurs. The stator current and the input power are minimized almost simultaneously. Therefore, in practice, the stator current can be used as the controlled variable in the loss minimization procedure.

So, in the remaining part of this dessertation (see figures 4,5,6), the maximum efficiency and power factor will be cosidered as the main objective functions.

\section{5- SIMULATION RESULTS OF STRATEGIES}

The simulation is carried out on a three-phase induction motor, 380 Volt, $1 \mathrm{Hp}, 50 \mathrm{~Hz}$ and with 4 poles as follows [4]:

$\mathrm{R}_{\mathrm{S}}, \mathrm{R}_{\mathrm{r}}=0.0598,0.0403$,

$\mathrm{X}_{\mathrm{S}}, \mathrm{X}_{\mathrm{r}}=0.0364,0.0546$

$\mathrm{K}_{\mathrm{h}}=0.0380, \mathrm{C}_{\mathrm{str}}=0.0150$,

$\mathrm{C}_{\mathrm{fw}}=0.0093, \mathrm{~S}_{1}=1.07, \mathrm{~S}_{2}=-0.69, \mathrm{~S}_{3}=0.77$

Fig.(4) to Fig.(6) show the efficiency of the selected machine for all operating conditions at rated flux and using the proposed controller, respectively. 


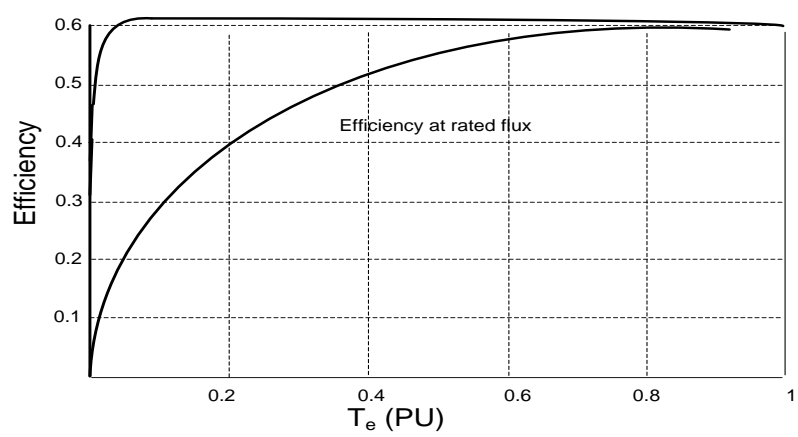

Fig.(4): The efficiency at rated speed=100 $\mathrm{rad} / \mathrm{sec}$.

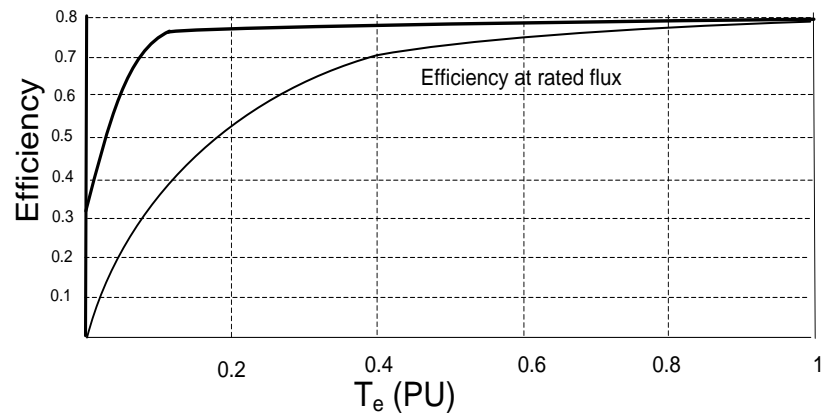

Fig.(5): The efficiency at rated speed=300 $\mathrm{rad} / \mathrm{sec}$.

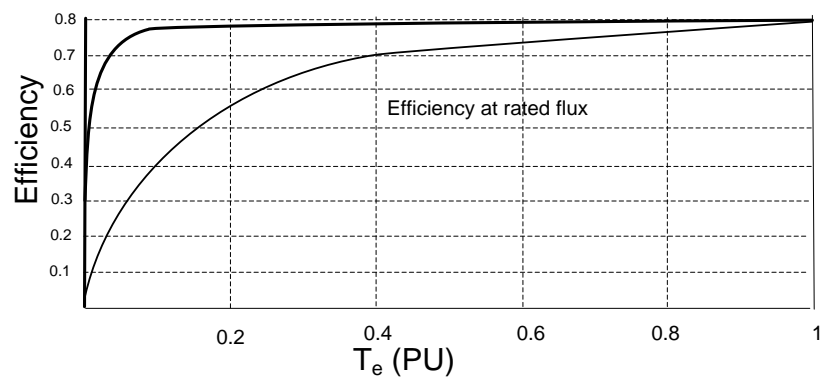

Fig.(6): The efficiency at rated speed=400 $\mathrm{rad} / \mathrm{sec}$.

From the figures, it is obvious that the efficiency decreases substantially when either the torque or rotor speed is small, the power factor increases at low values of rotor speed and the stator current is almost the same at a certain value of load torque with different values of rotor speed.

\section{6- CONCLUSIONS}

This paper deals with the applicability of the proposed controller to loss minimization control in induction motors. The proposed controller adaptively adjusts the slip frequency such that the drive is operated at the minimum loss. Simulation results show 
that a considerable energy saving is achieved in comparison with the conventional method of operating under the condition of constant voltage to frequency ratio.

\section{REFERENCES}

[1] Moreno-Eguilaz, J.; Cipolla, M.; Peracaula, J.; da Costa Branco, "Induction motor optimum flux search algorithms with transient state loss minimization using a fuzzy logic based supervisor", Power Electronics Specialists Conference, 1997. PESC ' 97.

[2] Ojo, O.; Dong, G.; "Efficiency optimizing control of induction motor using natural variables", Applied Power Electronics Conference and Exposition, 2004. APEC '04.

[3] K. M. Hasan, Li Zhang, B. Singh, "Neural network control of induction motor drives for energy efficiency and high dynamic performance", Industrial Electronics, Control and Instrumentation, 1997.

[4] Abdin, E.S.; Ghoneem, G.A.; Diab, H.M.M.; Deraz, S.A.; "Efficiency optimization of a vector controlled induction motor drive using an artificial neural network", Industrial Electronics Society, Volume 3, 2-6 Nov. 2003, PP. $2543-2548$.

[5] Poirier, E.; Ghribi, M.; Kaddouri, A.; "Loss minimization control of induction motor drives based on genetic algorithms", Electric Machines and Drives Conference, 2001. IEMDC 2001. IEEE International 2001, PP. 475 - 478.

[6] M. Kouki et al. "High-response flux control of direct - field-oriented induction motor with high efficiency taking core loss into account", IEEE Trans. on Industry Applications, Vol. 35, No. 1, pp. 62-69, January-Feburary 1999.

[7] Blaabjerg, F; Pedersen, J.K.; Thoegersen, P.B.; "Efficiency-optimized control of medium-size induction motor drives", Industry Applications, IEEE Transactions, Volume 37, Issue 6, Nov.-Dec. 2001, PP. 1761 - 1767.

[8] R.J.Spiegel; M.W. Turner; Fuzzy-logic-based controllers for efficiency optimization of inverter-fed induction motor drives, RTI International, Volume 137, Issue 3 (August 2003).

[9] Johnson, Andrew P.; High-speed linear induction motor efficiency optimization; Massachusetts Inst. of Technology, Cambridge, June 2005.

[10] Brian T. Branecky; Method and apparatus of improving the efficiency of an induction motor, Milauakee Journal Sentinel, No. 713343, filed on 2007-11-14; October 2007.

[11] S. Vaez-Zadeh and F. Hendi; A continuous efficiency optimization controller for induction motor drives, Elsevier, Volume 46, Issue 5, March 2005, PP. 701713. 


\section{استراتيجية للتحمم مبنية على النمذجة الرياضية لمحرك حثي}

تعرض هذه الورقة تطبيقا لتحكم ذكي في تتغيل محرك حثي، ويتم فيها اقتراح استراتيجية للتحكم بسرعة

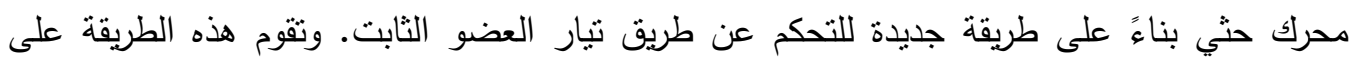

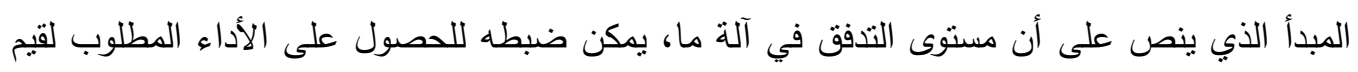

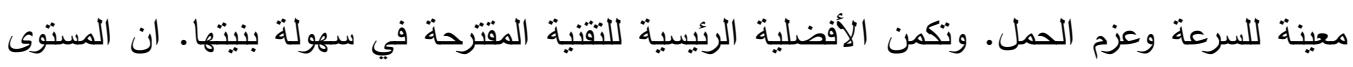

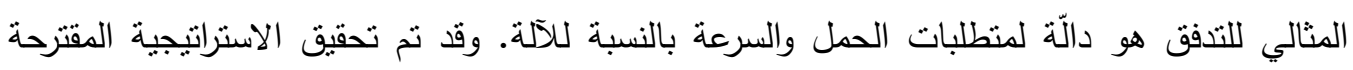
بطريقة التتغيل تحت شرط نسبة ثابتة للجهد الى التزدد. وتم الحصول على نتائج المحاكاة الحاسوبية لإلثات فاعلية الطريقة المقترحة. 